\title{
EMF32 RESULTS FROM NEMS: REVENUE RECYCLING*
}

\author{
VIPIN ARORA ${ }^{\dagger}$, DAVID DANIELS, IAN MEAD and RUSSELL TARVER \\ U.S. Energy Information Administration \\ 1000 Independence Ave. SW, Washington DC, 20585, USA \\ †vipin.arora@eia.gov
}

Received 28 August 2017

Revised 21 December 2017

Accepted 3 January 2018

Published 20 March 2018

\begin{abstract}
We show results from the National Energy Modeling System generated during the Energy Modeling Forum 32 study - focusing on macroeconomic responses to different methods of recycling carbon tax revenue. We find that recycling such revenue directly to consumers in the form of lump sum payments results in smaller negative GDP impacts than using the revenues to reduce business taxes.
\end{abstract}

Keywords: Credit; carbon tax; revenue recycling; economic activity.

JEL Classifications: E17, E60, Q43, Q50

\section{Introduction}

Under a policy that is expected to produce significant government revenues - such as a carbon tax - the way such revenues are used can play a critical role in determining the impacts on both the energy system and the broader economy. While detailed energy-sector models of the US can be used to understand the behavioral impacts of policies aimed at reducing carbon dioxide emissions on the energy system itself, economy-wide macroeconomic models are employed to understand the impacts of those policies on the broader economy. Relatively, few studies have considered such policies in a fully integrated energy/economic framework.

In this paper, we use such an integrated energy-economy framework - as implemented in the National Energy Modeling System (NEMS) (2017) - to explore the impacts of a carbon tax and revenue recycling scheme on the US economy, as specified

\footnotetext{
*The analysis and conclusions expressed here are those of the authors and not necessarily those of the US Energy Information Administration.

†Corresponding author.

This is an Open Access article published by World Scientific Publishing Company. It is distributed under the terms of the Creative Commons Attribution 4.0 (CC-BY) License. Further distribution of this work is permitted, provided the original work is properly cited.
} 
in a recent Energy Modeling Forum study on greenhouse gas policies and revenue recycling (EMF32).

NEMS is a widely employed model of the US energy-economy that produces the Energy Information Administration's (EIA's) Annual Energy Outlook (AEO). It has also been used in the past to conduct modeling and analysis similar to that undertaken in EMF32 (Cullenward et al., 2016; Wilkerson, 2014; Brown et al., 2012; Morrow et al., 2010; Kydes, 2007; Kreutzer and Dayaratna, 2013).

The salient features of NEMS, including a description of its macroeconomic model and its configuration for EMF32, are described in Sec. 2. Section 3 presents the results of the EMF32 runs, highlighting the similarities and differences across scenarios. Finally, in Sec. 4, we discuss the implications of the NEMS results for future energy system modeling exercises.

\section{Overview of the National Energy Modeling System (NEMS)}

We use the version of NEMS that produced the Annual Energy Outlook 2016 (AEO2016) in this paper (U.S. Energy Information Administration, 2016). NEMS is an energy-economy modeling system of the US. It projects production, imports, conversion, consumption, and prices of energy - subject to assumptions about macroeconomic and financial conditions, demographic trends, global energy markets, resource availability and costs, behavioral and technology choice criteria, and cost and performance characteristics of energy technologies. NEMS was designed and implemented by EIA in 1993, and has been used to make projections for EIA's Annual Energy Outlook since 1994.

The architecture of NEMS is modular (see Fig. 1), with four end-use modules, two energy conversion modules, four supply modules, a macroeconomic module and an integration module. NEMS is a partial equilibrium model with macroeconomic

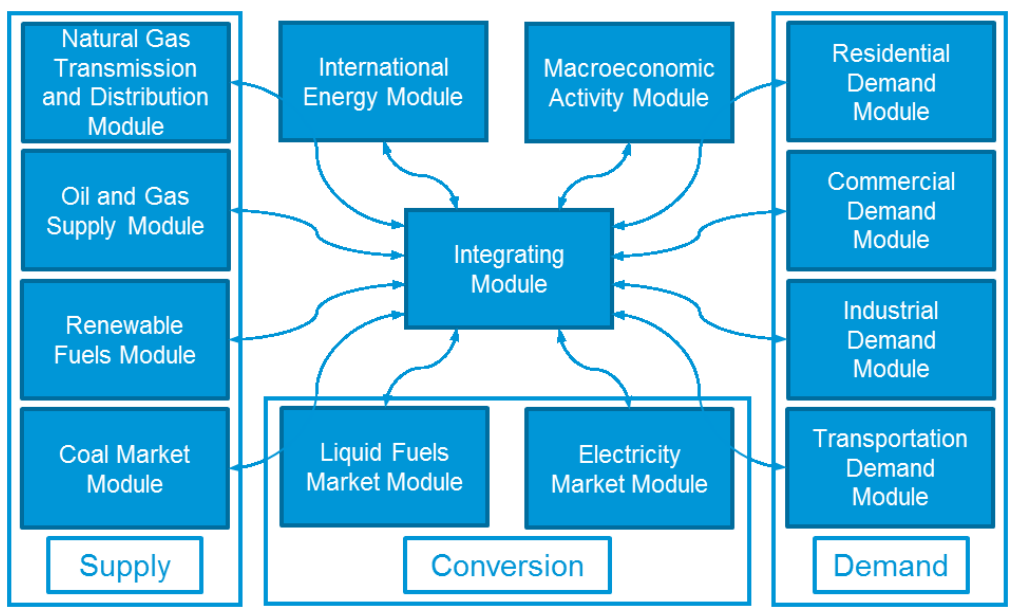

Figure 1. NEMS architecture. 
feedback: while each module finds its own partial equilibrium solution that balances supplies with demands, the macroeconomic module provides a mechanism for incorporating economy-wide impacts of these solutions back into the other modules. For instance, the impacts of changing energy commodity prices on the gross output of industrial subsectors is computed by the macroeconomic module, and these gross output estimates are then used by the industrial demand module to project fuel consumption.

The Macroeconomic Activity Module (MAM) links NEMS to the rest of the economy by providing projections of economic driver variables for use by the supply, demand, and conversion modules (U.S. Energy Information Administration, 2016). Economic activity driving the National Energy Modeling System (NEMS) is determined by an economic modeling system comprising three sets of models:

- IHS/Markit Inc.'s model of the US economy,

- IHS/Markit Inc.'s industrial output and employment by industry models,

- US Energy Information Administration's (EIA) regional models.

IHS/Markit Inc.'s model of the US economy (the US model) is the same model used by the company to produce its economic forecasts of the American economy. EIA's Industrial Output and Employment by Industry Models are derivatives of IHS/Markit Inc.'s industrial output and employment by industry models. The models have been tailored in order to provide the industrial output and employment by industry detail required by NEMS. EIA's regional models consist of models of economic activity, industrial output, employment by industry and commercial floor space.

All of the MAM models are linked to provide a fully integrated approach to estimating economic activity at the national, industrial and regional levels. The US model determines the national economy's growth path and the final demand mix. EIA's Industrial Output Model ensures that supply by industry is consistent with the final demands (consumption, investment, government spending, exports and imports) calculated elsewhere in the MAM.

The US model produces the key output variables used in this study. It is a macroeconometric model: a system of estimated behavioral equations and identities (US Energy Information Administration, 2016). Stochastic equations are usually based at least in part on theory and are estimated using historical data, whereas identities are equations that hold by definition. These equations comprise of both endogenous and exogenous variables. The values of endogenous variables are determined in the model; they are the solution to model equations. Exogenous variables come from outside the model structure.

Roughly speaking, the short-run structure of the US model is based on IS-LM theory so that outcomes are demand determined (see Mankiw (2015) for more detail on the standard macroeconomic theory embodied in the US model). The IS curve summarizes the relationship between the real interest rate and the level of income that 
arises in the market for goods and services. The LM curve plots the relationship between the real interest rate and the level of income that arises in the market for money balances. The intersection of these two curves gives the equilibrium real interest rate and income.

As with most macroeconometric models, the US model has an implied relationship between output and inflation in the short-run. That is, by increasing output a policymaker can potentially increase output at the cost of higher inflation. This relationship only holds in the short-run. After 5-7 years there is a transition to the long-run, and the supply-side of the economy becomes more important. The model's longer-run supply properties are based on standard growth theory, the model of Solow and Swan.

\section{Key Results from EMF32 Scenarios}

We assigned an exogenous, time-dependent carbon price to emissions from consumption of fossil fuels in the energy sector for each EMF32 model run. Carbon taxes have an initial value of either $\$ 25$ or $\$ 50$ per metric ton of $\mathrm{CO}_{2}(\$ 2010)$ beginning in 2020 , and grow in real terms by either $1 \%$ or $5 \%$ a year thereafter. The four possible carbon tax trajectories are labeled $\$ 25 / 1 \%, \$ 25 / 5 \%, \$ 50 / 1 \%$, and $\$ 50 / 5 \%$. By 2040 , these taxes have reached $\$ 30, \$ 66, \$ 61$, and $\$ 133$, respectively. The projections run through 2040, consistent with the version of NEMS used to generate the AEO2016.

Consumption of each fossil fuel, along with the fuel's carbon intensity, are used along with the carbon prices to estimate annual government revenues from these taxes. The tax revenues are recycled back into the economy either as direct lump sum payments to consumers (LS) or used to offset losses from a decrease in business tax revenue associated with a reduction in corporate income tax rates (DT). Along with the four carbon tax trajectories, these revenue recycling options result in a total of eight runs. ${ }^{1}$

Figures 2 and 3 show $\mathrm{CO} 2$ emissions from electric power generation as well as from non-electricity-related fossil fuel consumption in the residential, commercial, industrial, and transportation sectors from the two most different carbon tax trajectories, $\$ 25 / 1 \%$ and $\$ 50 / 5 \%$, assuming LS recycling. While the tax creates carbon mitigation impacts across all sectors, electricity generation is most impacted through 2040. The results are similar for the corresponding DT recycling cases. This is consistent with the finding in Appendix A.7 of (Wilkerson, 2014) that the choice of revenue recycling option in NEMS has little impact on carbon emissions.

\footnotetext{
${ }^{1}$ Mechanically, these scenarios were implemented in the MAM mcevcode.txt file using several different options. The LS cases use NEMS flag MACTAX (TAXMODE $=4)$. The collected revenues are subtracted from the add factor for federal personal income tax receipts (TXPGF_A). These runs are deficit neutral. Federal personal tax receipts (TXPGF) are solved for the given baseline for full-employment federal NIPA budget surplus (NETSAVGFFE) and collected revenues. The DT cases use NEMS flag MACTAX (TAXMODE=5). The collected revenues are subtracted from add factor for federal corporate tax receipts (TXCORPGF_A). These runs are deficit neutral. Federal corporate tax receipts (TXCORPGF) are solved for the given baseline for full-employment federal NIPA budget surplus (NETSAVGFFE) and collected revenues.
} 


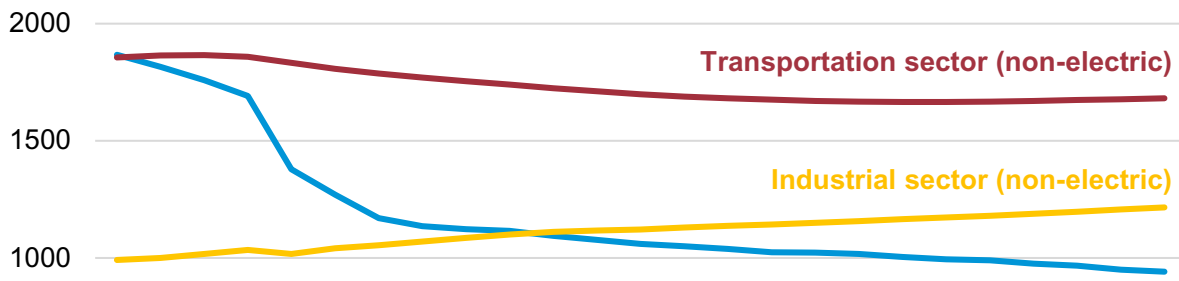

Electric power generation

500

Residential sector (non-electric)

Commercial sector (non-electric)

0 $\begin{array}{lllllll}2016 & 2020 & 2024 & 2028 & 2032 & 2036\end{array}$

Figure 2. CO2 emissions, million metric tons, \$25/1\%/LS.

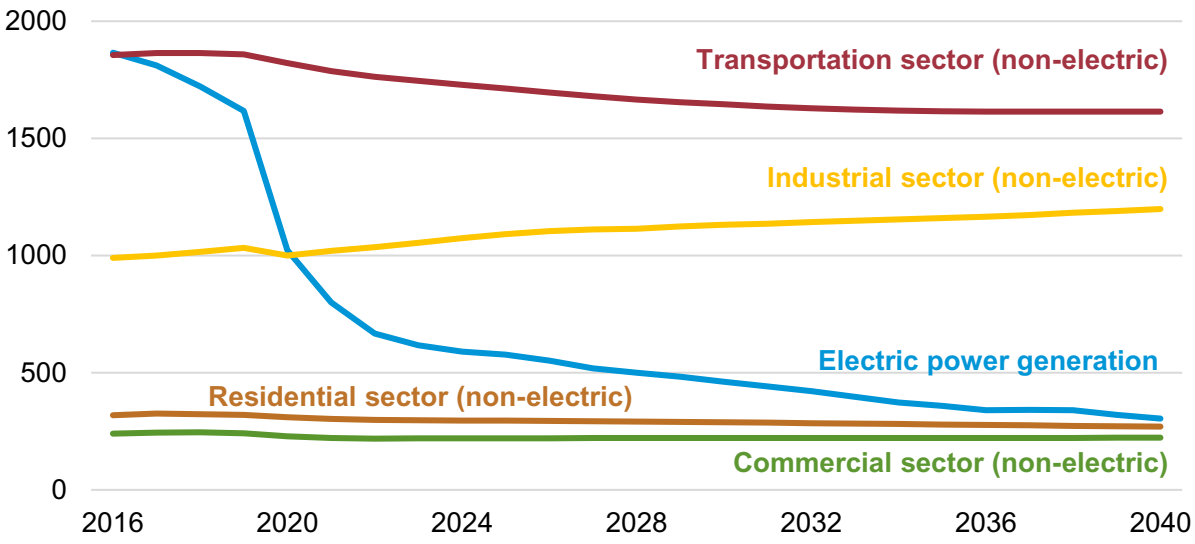

Figure 3. $\mathrm{CO} 2$ emissions, million metric tons, $\$ 50 / 5 \% / \mathrm{LS}$.

Figures 4-7 show select macroeconomic results from the four carbon tax runs that begin at $\$ 25$ in 2020 . For ease of comparison, all figures are shown as percentage changes from a base case in which there is no carbon tax throughout the projection period.

The relative impacts on energy consumption, personal consumption expenditures, investment, and GDP are all negative across the four scenarios throughout the entire projection period. NEMS does not observe a double dividend in these cases. Although the macro module of NEMS does not employ foresight, energy consumption nevertheless begins to decrease prior to 2020 because some of the other NEMS modules make capacity decisions before 2020 that incorporate the future expected higher energy prices. This change in energy consumption affects the rest of the economy as well.

A general pattern can be observed in the relative behaviors of energy consumption, personal consumption expenditures, investment, and GDP across all carbon tax cases. 


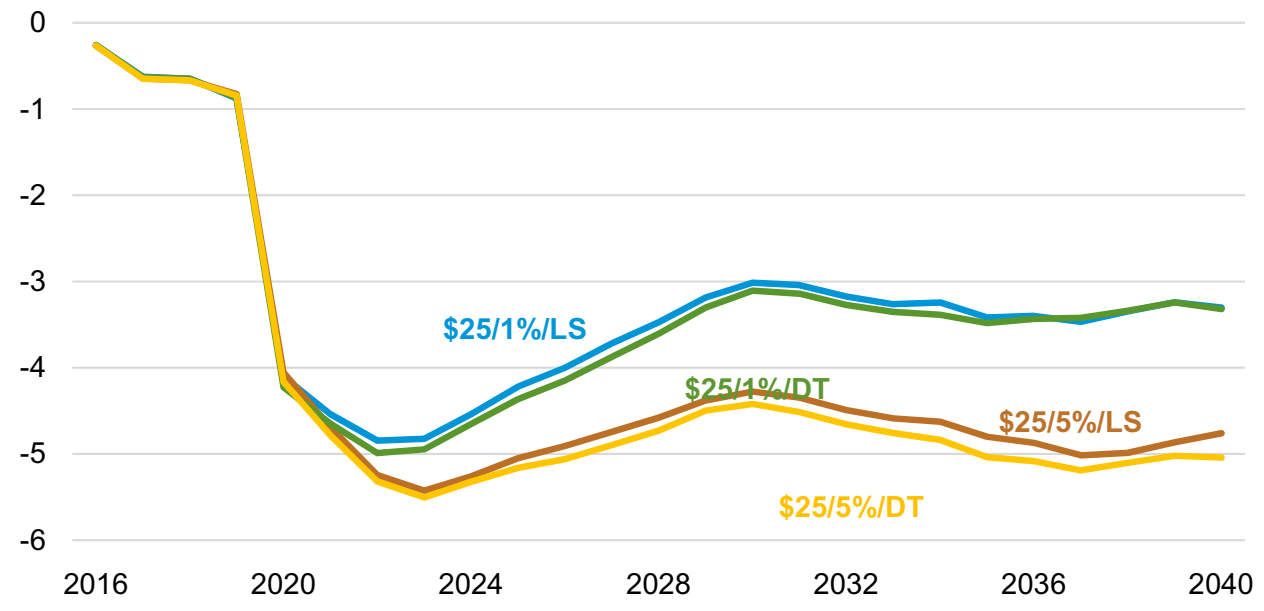

Figure 4. Energy consumption, percent change from base.

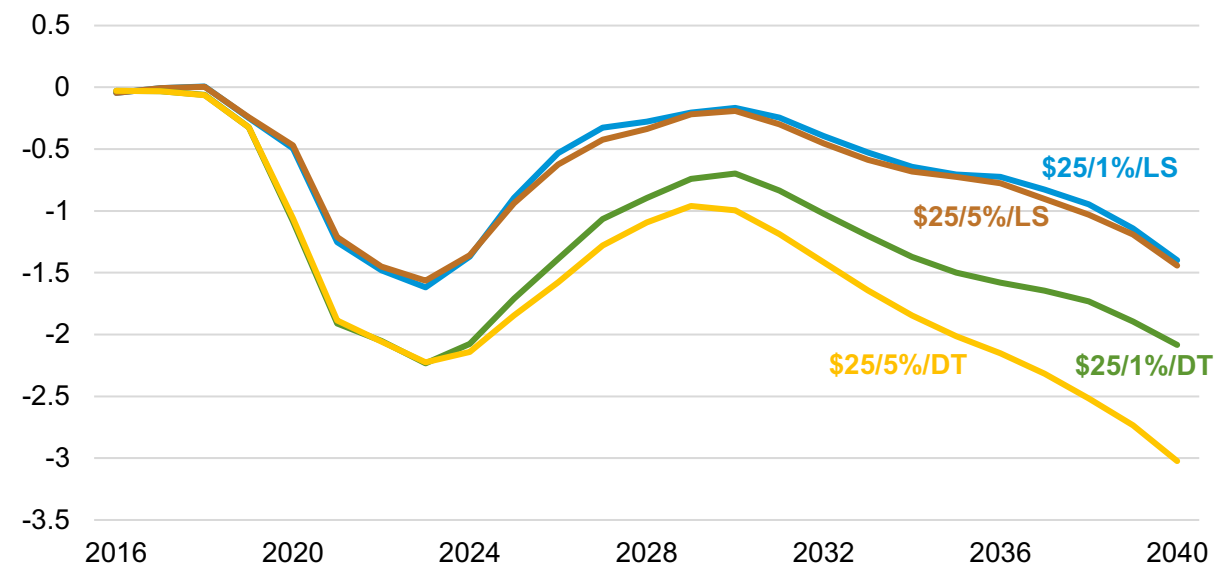

Figure 5. Real consumption, percent change from base.

Following a large and prompt negative response to the onset of carbon pricing in 2020, there is a gradual relative recovery for approximately 10 years before another more gradual downturn through the 2040 projection horizon. It is unclear if this last period represents a long-run dynamic equilibrium trajectory or one part of a cyclical pattern that could turn again after the projection period. The pattern is driven by the interplay of energy prices and macroeconomic growth (see the appendix for charts on how electricity prices change across the cases). Its appearance and consistency across all cases suggests it to be a persistent model feature of the MAM.

The two $\$ 25 / 1 \%$ cases (LS, DT) have similar energy consumption trajectories, as do the two $\$ 25 / 5 \%$ cases, suggesting that energy prices, which incorporate the carbon tax, 


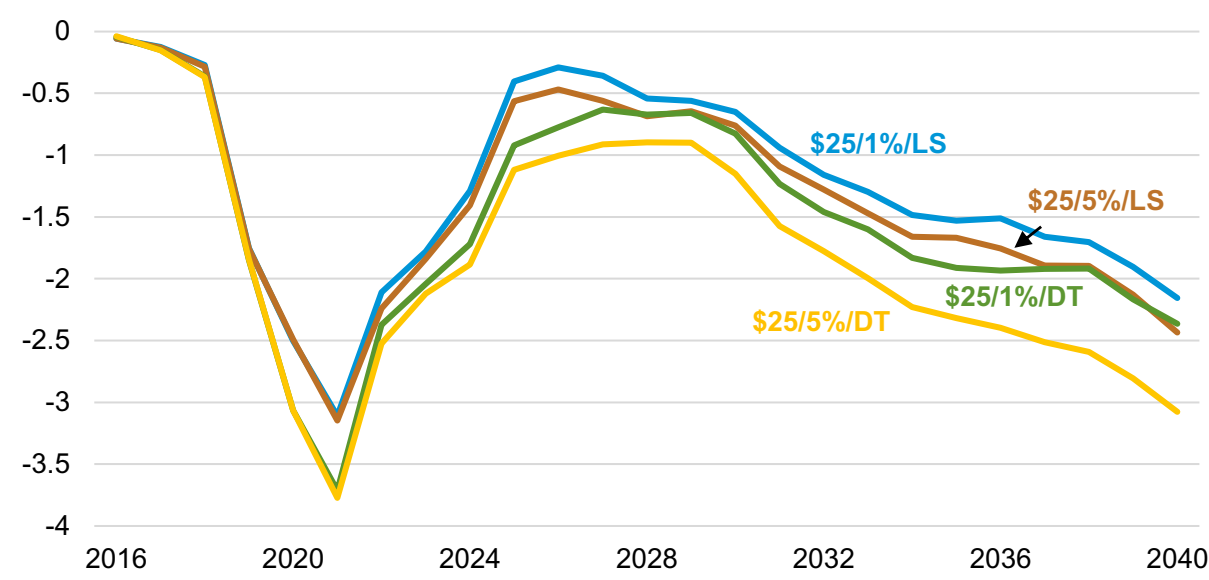

Figure 6. Real investment, percent change from base.

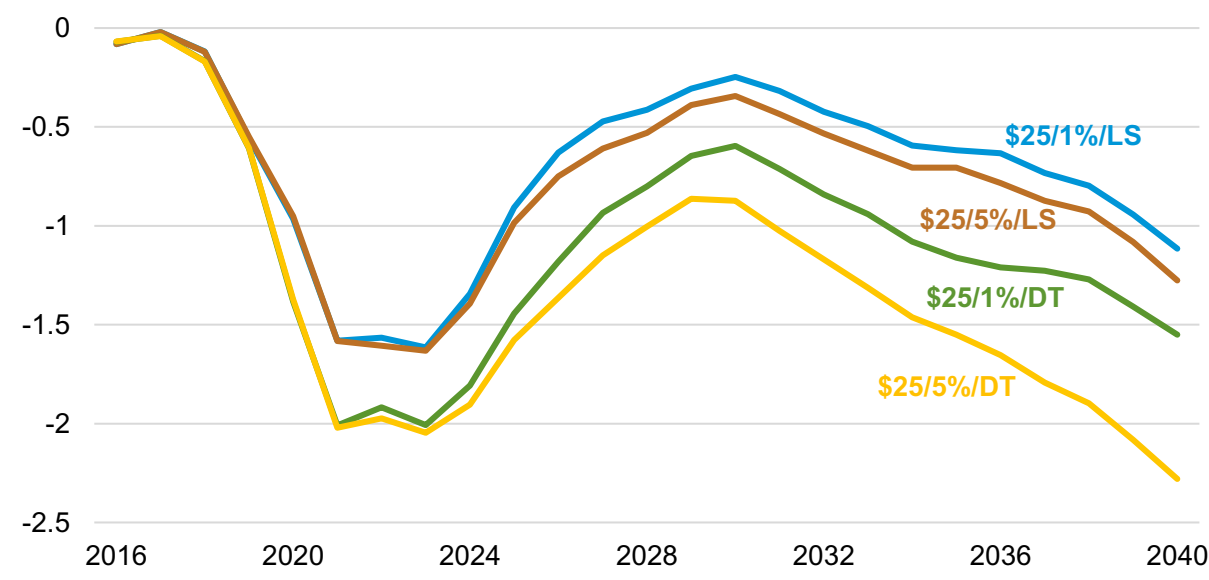

Figure 7. Real GDP, percent change from base.

drive energy consumption more than the revenue recycling mechanism. In both sets of cases, relative energy consumption hits a minimum in 2022 or 2023, recovers slightly throughout the rest of that decade, and then remains more or less stable throughout the 2030 's, even though prices continue to rise due to the increasing carbon tax.

Real consumption, investment, and GDP behave differently from energy consumption in the $\$ 25$ carbon tax scenarios. While energy prices appear to be the primary driver of differences in energy consumption across these four cases, revenue recycling seems to have a larger impact on economy-wide consumption, investment, and GDP: the two LS cases track each other closely and are distinct from the two DT cases. This is especially apparent in the first few years of carbon taxes, when the $\$ 25 / 1 \%$ and 
Table 1. $\mathrm{CO}_{2}$ tax trajectories (2010\$).

\begin{tabular}{lrrrrr}
\hline Tax trajectory & 2020 & 2025 & 2030 & 2035 & 2040 \\
\hline$\$ 25 / 1 \%$ & $\$ 25.00$ & $\$ 26.28$ & $\$ 27.62$ & $\$ 29.02$ & $\$ 30.51$ \\
$\$ 25 / 5 \%$ & $\$ 25.00$ & $\$ 31.91$ & $\$ 40.72$ & $\$ 51.97$ & $\$ 66.33$ \\
$\$ 50 / 1 \%$ & $\$ 50.00$ & $\$ 52.55$ & $\$ 55.23$ & $\$ 58.05$ & $\$ 61.01$ \\
$\$ 50 / 5 \%$ & $\$ 50.00$ & $\$ 63.82$ & $\$ 81.45$ & $\$ 103.95$ & $\$ 132.67$ \\
\hline
\end{tabular}

$\$ 25 / 5 \%$ cases show similar impacts on the consumption, investment, and GDP, even as the carbon taxes diverge. Economy-wide consumption patterns are remarkably similar in the $\$ 25 / 1 \% / \mathrm{LS}$ and $\$ 25 / 5 \% / \mathrm{LS}$ cases throughout the projection, even though Table 1 shows that the carbon tax in the $\$ 25 / 5 \% / \mathrm{LS}$ case is more than twice as large as in the $\$ 25 / 1 \% / \mathrm{LS}$ case by 2040 . This suggests that the macroeconomic impacts of a carbon tax in MAM are more sensitive to the initial 2020 shocks than they are to smaller $(1 \%$ to $5 \%)$ annual changes thereafter.

Furthermore, the relative changes in both consumption and investment are smaller for the LS cases than they are for the DT cases. Even the \$25/1\%/DT case has a greater negative impact on these three variables than the $\$ 25 / 5 \% / \mathrm{LS}$ scenario over the projection period to 2040, although the investment levels in these two cases are close to each other after the mid-2020s.

Figures $8-11$ show the same variables for the four $\$ 50$ carbon tax scenarios. Qualitatively, the results are similar to the $\$ 25$ cases, but the impacts are correspondingly greater - the $\$ 50$ carbon tax cases have a $25 \%$ to $50 \%$ greater magnitude effect than the corresponding $\$ 25$ cases. There are a few unique features to the $\$ 50$ runs.

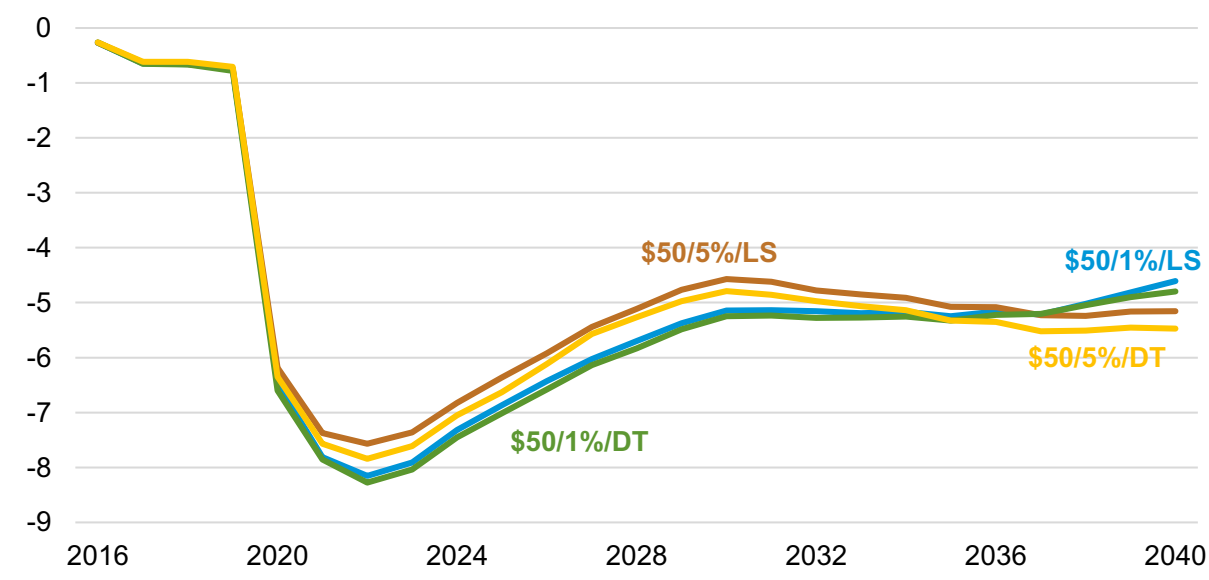

Figure 8. Energy consumption, percent change from base. 


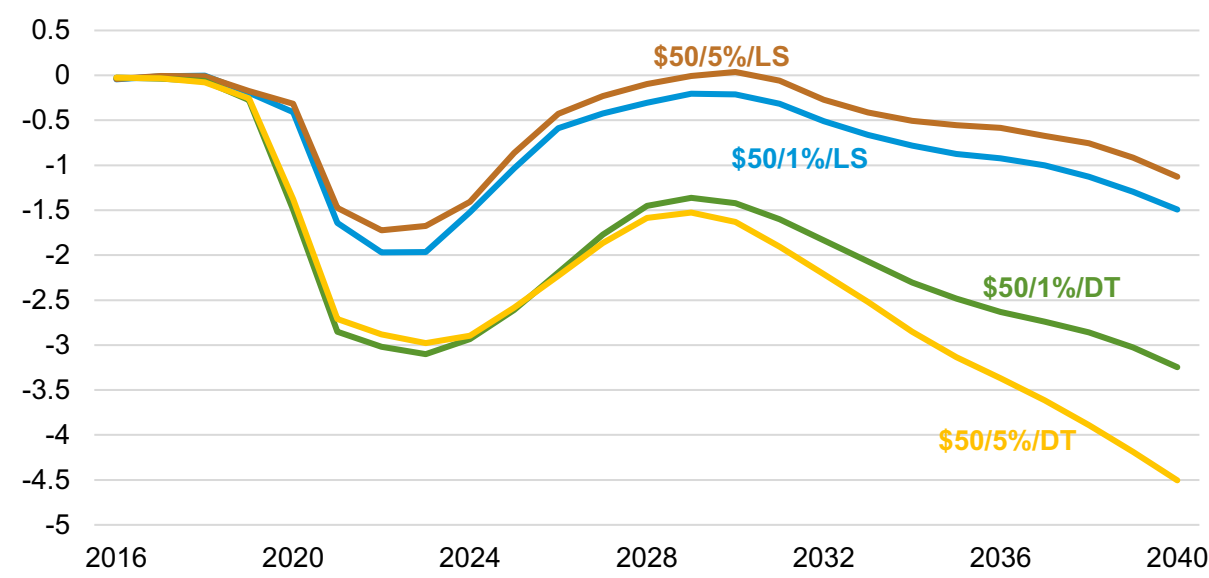

Figure 9. Real consumption, percent change from base.

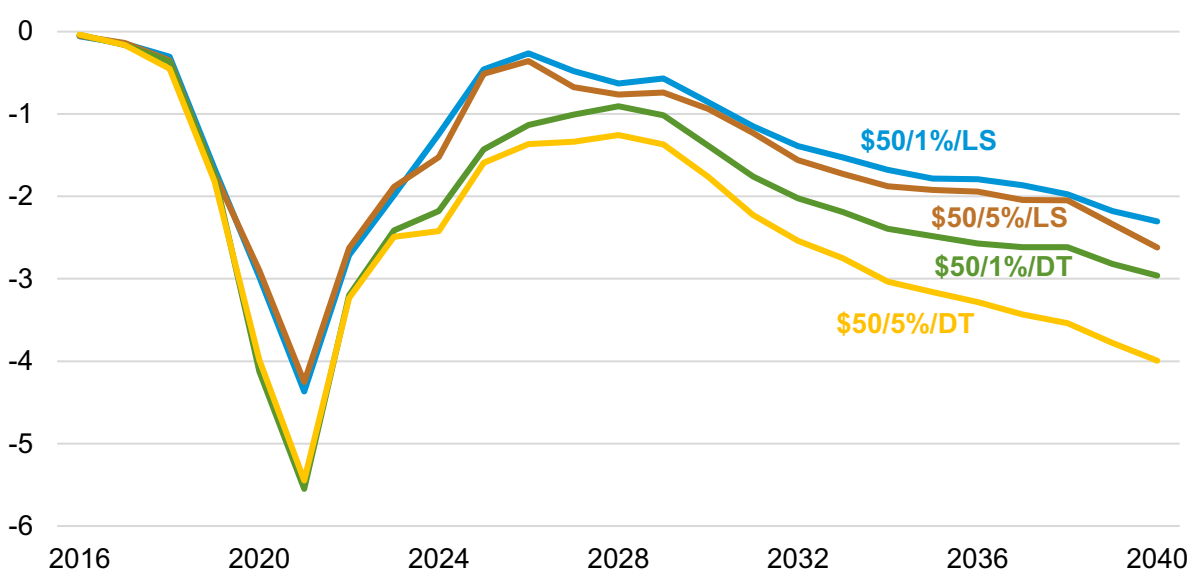

Figure 10. Real investment, percent change from base.

Energy consumption appears to be reduced slightly less in the $\$ 50 / 5 \%$ cases than in the $\$ 50 / 1 \%$ cases through the mid-2030's. This is a somewhat counterintuitive result, and is different from the $\$ 25 \mathrm{CO}_{2}$ cases. Similarly the $\$ 50 / 5 \% / \mathrm{LS}$ scenario has a smaller impact on consumption and GDP than the \$50/1\%/LS scenario. This reversal of the ordering of consumption, however, does not extend to the DT scenarios. All of these effects are small, and it is unclear whether they are significant. It is possible that MAM is very sensitive to large discontinuities in energy prices and much less so to small annual changes or to price levels.

Figures $12-15$ show the four scenarios with $1 \%$ carbon tax growth rates. These have been shown in previous figures, but are collected here to highlight the impacts of carbon price levels and revenue recycling. 


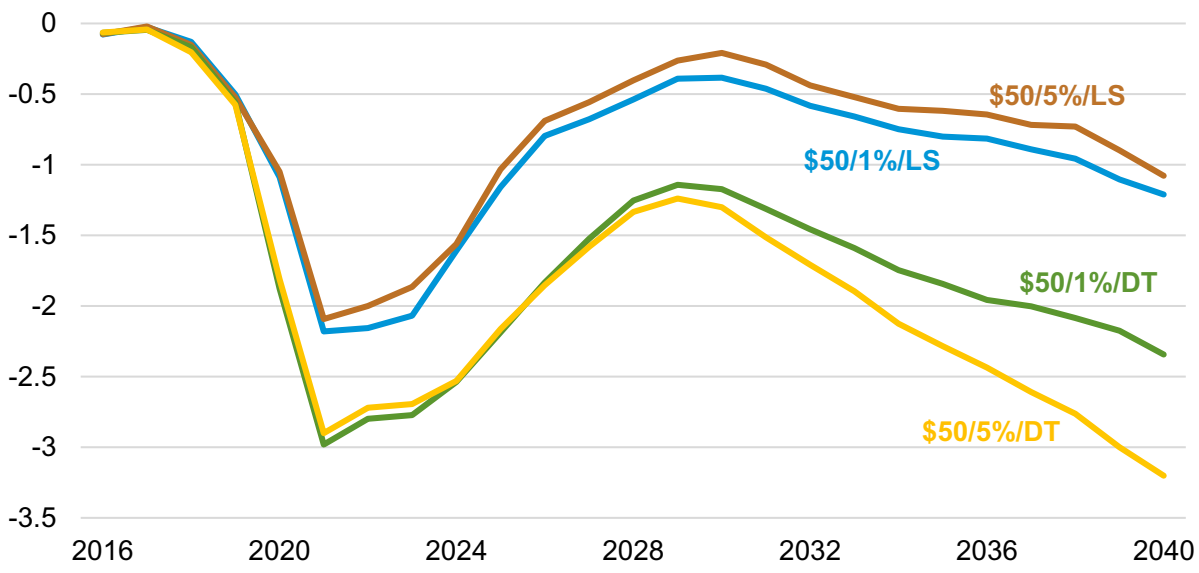

Figure 11. Real GDP, percent change from base.

As discussed above, energy consumption is very sensitive to carbon prices: the $\$ 50$ cases show energy consumption decreasing about two-thirds more, relative to baseline, than the $\$ 25$ cases. Revenue recycling shows little additional impact on energy consumption. Similarly to the results compared in Fig. 8, Fig. 12 shows that the price escalation, $1 \%$ or $5 \%$, has almost no impact on energy consumption. This may suggest that MAM is nonlinearly sensitive to annual energy price changes.

Real consumption, on the other hand, is much more sensitive to revenue recycling, with lump sum recycling back to households causing a smaller decrease in consumption than decreasing business taxes. As an example, the $\$ 50 / 1 \% / \mathrm{LS}$ scenario has a smaller negative impact on consumption than the $\$ 25 / 1 \% / \mathrm{DT}$ case, because even though prices are higher more revenues are being recycled back to consumers in the

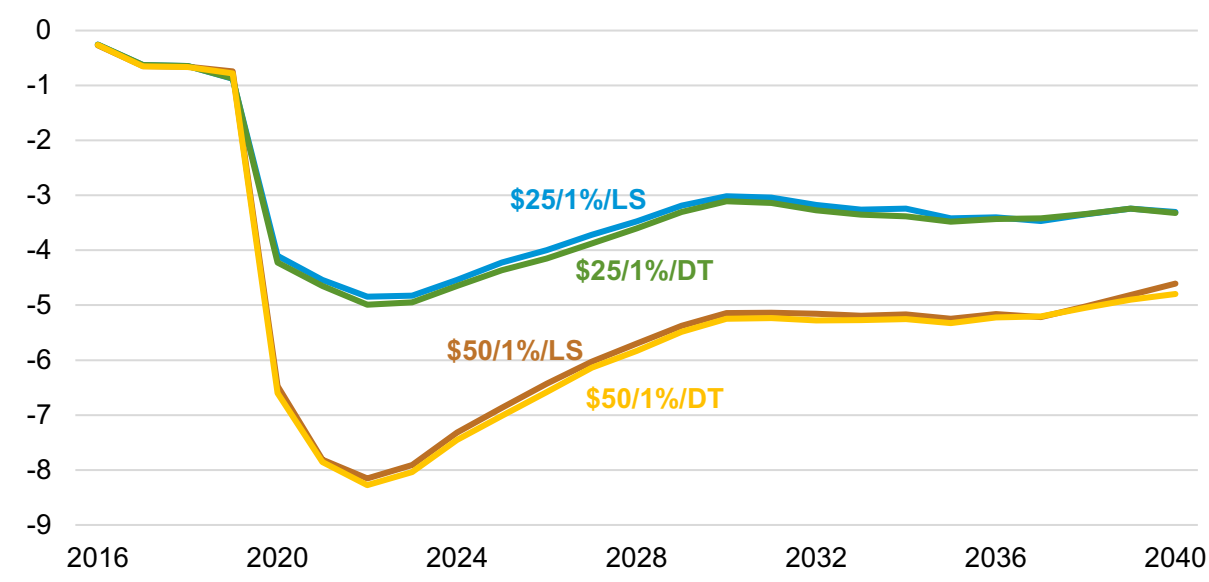

Figure 12. Energy consumption, percent change from base. 


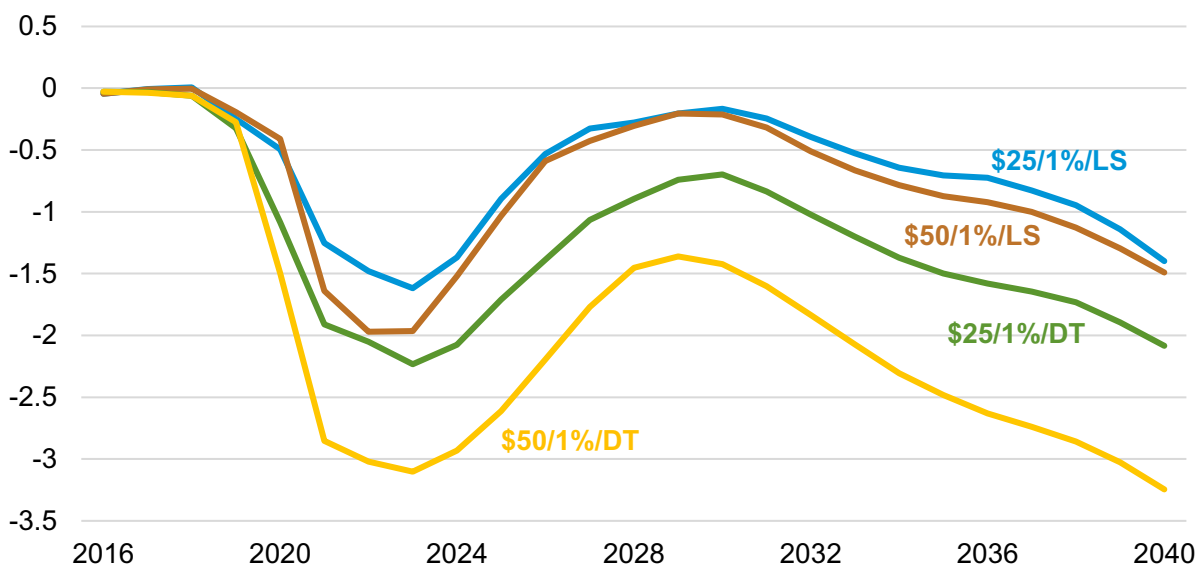

Figure 13. Real consumption, percent change from base.

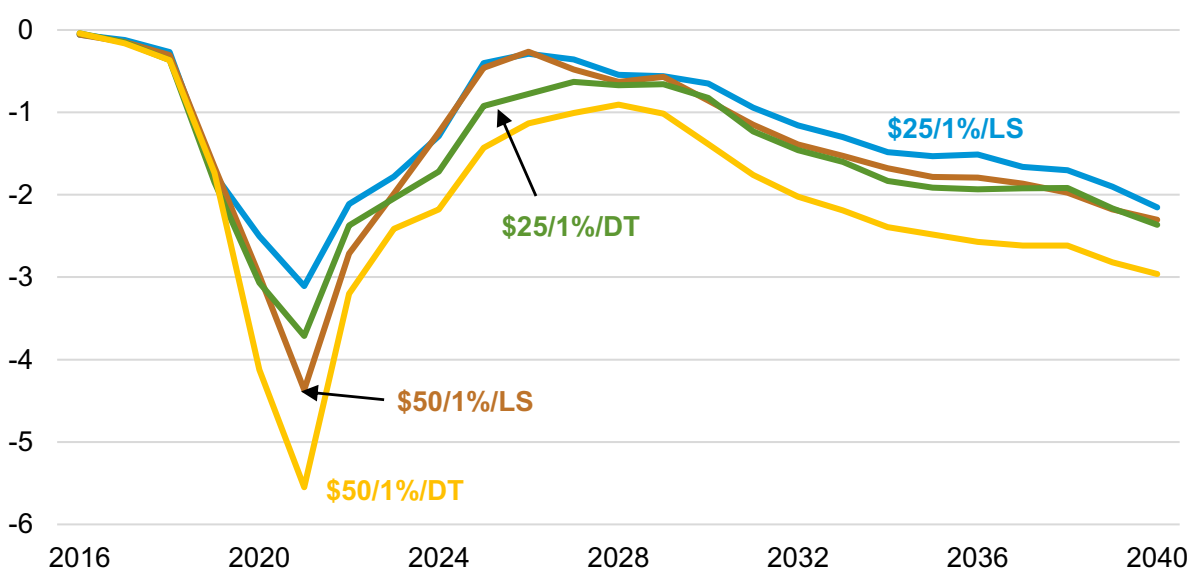

Figure 14. Real investment, percent change from base.

former case. Of note is that the DT cases also appear to be more sensitive to the level of the carbon tax than the LS cases. Investment appears to be sensitive to annual changes in the carbon tax, with both $\$ 50$ tax cases seeing a greater initial decrease in investment - but also a steeper subsequent recovery than the $\$ 25$ cases.

As a consequence, the GDP paths for the \$25/1\%/DT and \$50/1\%/LS scenarios cross each other: initially, GDP in the $\$ 50 / 1 \% / \mathrm{LS}$ case falls more rapidly than the $\$ 25 /$ $1 \% / \mathrm{DT}$ case due to the greater decline in investment in the $\$ 50$ case. By the mid 2020 's, investment in the $\$ 50$ case has recovered, and the $\$ 50$ case has higher GDP throughout the rest of the projection period. The 5\% cases have similar trends and are not shown here. 


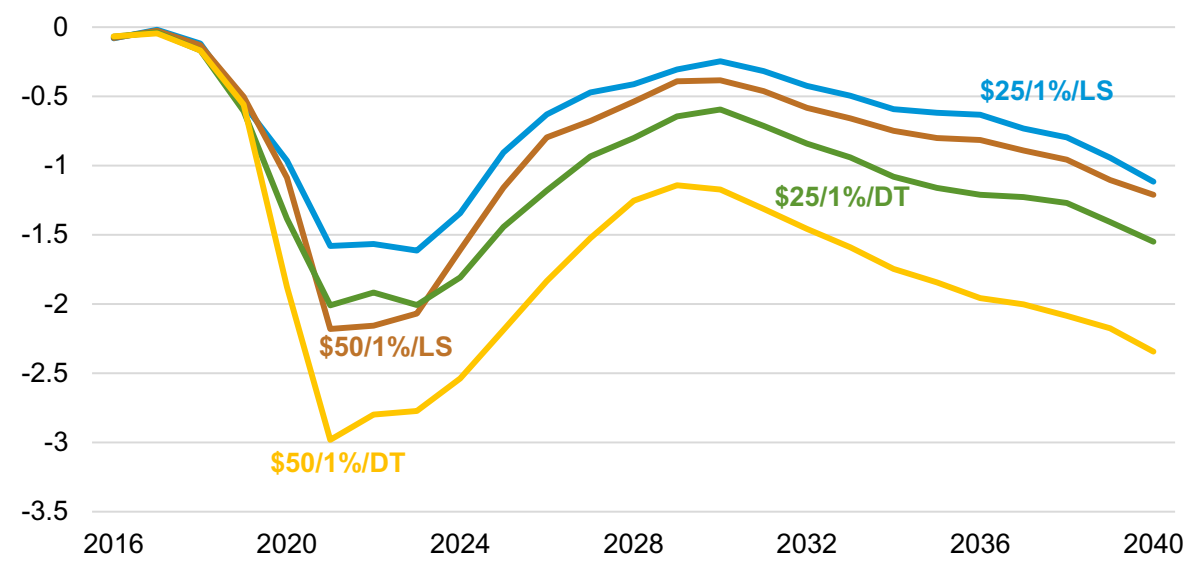

Figure 15. Real GDP, percent change from base.

\section{Conclusions}

Several general trends emerge in the eight cases (plus baseline) we examine in this paper. First, energy consumption appears to be more sensitive to the levels of the carbon price than it is to the revenue recycling scheme.

Second, real consumption, investment, and GDP appear to be primarily influenced by the choice of revenue recycling method, and secondarily to the magnitudes of (or changes in) the carbon tax itself. These variables are determined endogenously within MAM, and so reflect the structure and assumptions in the macroeconomic module of NEMS. The result shows a relatively minor influence of energy consumption on the larger economy.

Third, the marginal impacts on real consumption, investment, and GDP appear to be greater for government revenues recycled to households (LS) than for businesses via reductions in corporate tax rates (DT). Figures 13 and 14 provide some insight into the reasons for this.

Figure 13 shows that consumption reacts similarly under two LS scenarios in which carbon taxes differ by a factor of two. Energy consumption is affected differently by the two tax trajectories, but the greater revenues recycled back to households under the higher carbon tax offset this, allowing for greater non-energy consumption under an LS scenario.

In a DT scenario, higher energy prices lead to reduced energy consumption, and the correspondingly lower effective household income also reduces non-energy consumption. In the MAM, the revenue recycled into businesses in a DT scenario does not induce as much household spending as the same revenue recycled directly to households via a LS scenario.

Figure 14 shows that investment is systematically lower under a DT scenario than it is under an equivalent LS scenario. This suggests that the marginal propensity of 
businesses to invest is more sensitive to changes in consumption than it is to changes in business income.

\section{Appendix A}

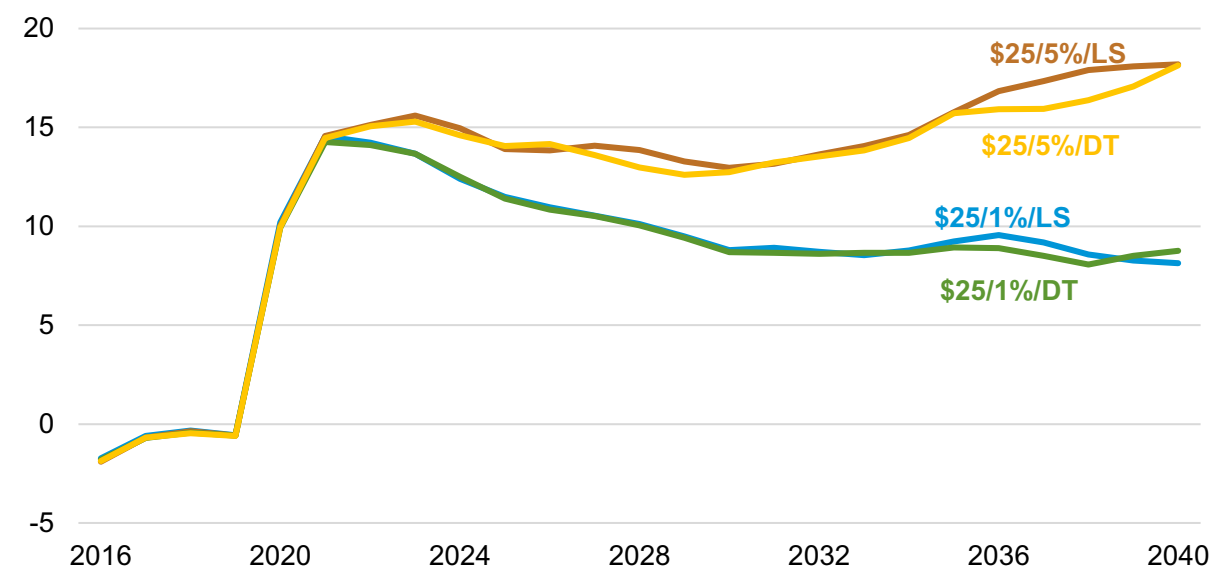

Figure A.1. Real electricity price, percent change from base.

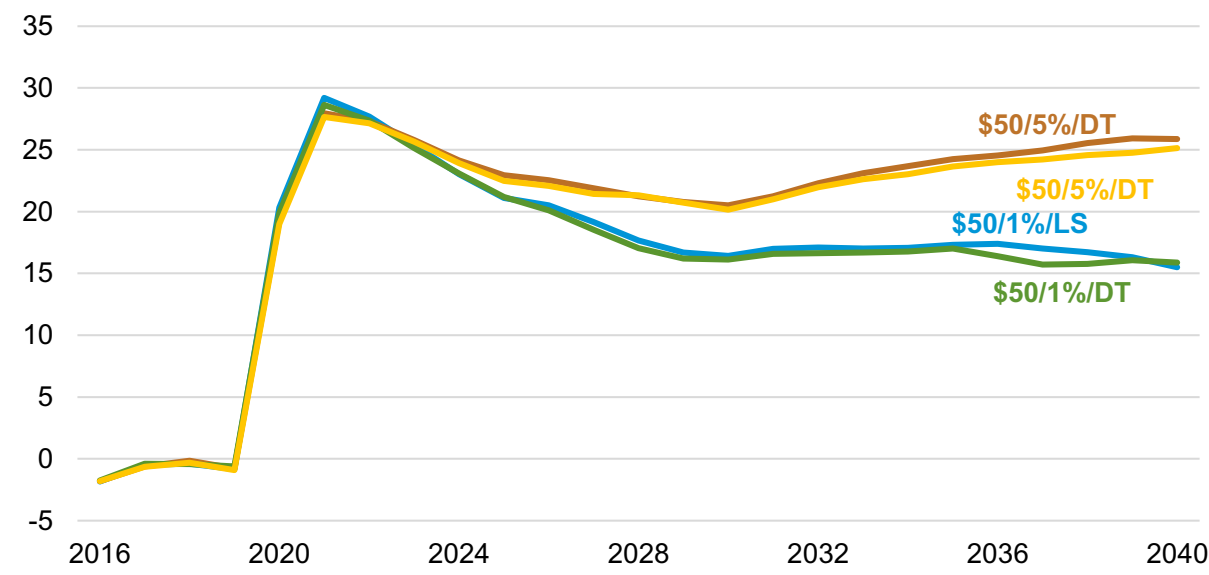

Figure A.2. Real electricity price, percent change from base. 


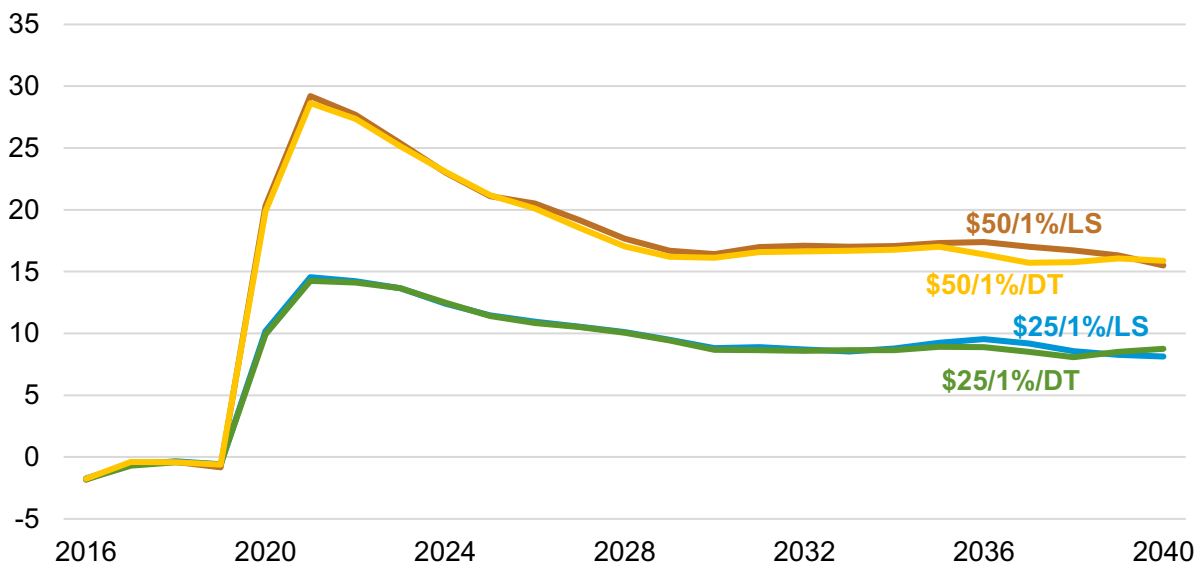

Figure A.3. Real electricity price, percent change from base.

\section{References}

Brown, M, M Cox and X Sun (2012). Modeling the impact of a carbon tax on the commercial buildings sector. In Proceedings of the ACEEE Summer Study on Energy Efficiency in Buildings.

Cullenward, D, J Wilkerson, M Wara and J Weyant (2016). Dynamically estimating the distributional impacts of U.S. climate policy with NEMS: A case study of the Climate Protection Act of 2013. Energy Economics, 55, 303-318.

Kreutzer DW and KD Dayaratna (2013). Boxer-Sanders Carbon Tax: Economic Impact. Available at http://www.heritage.org/taxes/report/boxer-sanders-carbon-tax-economic-impact.

Kydes, A (2007). Impacts of a renewable portfolio generation standard on US energy markets. Energy Policy, 35(2), 809-814.

Mankiw, NG (2015). Macroeconomics, 9th edn., Worth Publishers, New York, NY.

Morrow, WR, K Sims Gallagher, G Collantes and H Lee (2010). Analysis of policies to reduce oil consumption and greenhouse-gas emissions from the US transportation sector. Energy Policy, 38(3), 1305-1320.

U.S. Energy Information Administration (2016). Annual Energy Outlook 2016. August. Available at https://www.eia.gov/outlooks/aeo/pdf/0383(2016).pdf.

U.S. Energy Information Administration (2016). MAM Documentation. Available at https:// www.eia.gov/outlooks/aeo/nems/documentation/macroeconomic/pdf/m065(2016).pdf.

U.S. Energy Information Administration (2017). NEMS documentation. 17 May. [Online]. Available at https://www.eia.gov/outlooks/aeo/nems/documentation/. [Accessed on 17 May 2017].

Wilkerson, J (2014). Economic and Distributional Impacts from Carbon Fee and Dividend Policies. PhD Dissertation, Stanford University. 